\title{
Sonora en el nuevo proyecto expansionista de Estados Unidos: las maquiladoras de exportación y la Ford Motor Co.*
}

\author{
José Carlos Ramírez**
}

Este trabajo presenta un análisis de interpretación del significado y naturaleza dei papel que han jugado los capitales estadunidenses en la vida económica de Sonora en los últimos cien años, con especial énfasis en el periodo 1963-1988, que condensa las formas más avanzadas de la inversión norteamericana en el Estado. Se tomó como unidad de análisis a las maquiladoras y a la empresa Ford. El estudio intenta deslindar qué parte de la evolución económica de Sonora se debe al capital nacional y qué parte al extranjero. Asimismo pretende demostrar que la nueva presencia estadunidense ha creado un segundo frente de reproduccción libre de cualquier influencia nacional importante.

\section{Introducción}

Si tuviéramos la paciencia para estudiar los acontecimientos económicos ocurridos en Sonora durante los últimos cien años, descubriríamos que pocos hechos han sido tan relevantes para la historia productiva de este estado como la omnipresencia de los capitales estadunidenses. Su abrumadora e indisputada participación en las actividades que han regido el destino económico de la sociedad en este periodo, ha hecho de la inversión norteamericana un fenómeno inherente a la reproducción capitalista de Sonora. De ahí que su referencia sea un tema ineludible para cualquier estudioso que intente explicar a fondo el desarrollo económico contemporáneo de la entidad.

Sin embargo, hay que tener cuidado en no uniformar la importancia económica de la participación estadunidense, ni de conferirle siempre el mismo nivel de influencia, pues ésta ha variado en significado y naturaleza a lo largo de tres grandes etapas: ${ }^{1}$ en una primera, de 1890 a 1929 , los capitales norteamericanos actuaron como propietarios directos del proceso productivo no sólo en las ramas clave del complejo minero-pecuario

\footnotetext{
* Este trabajo es una versión modificada del capítulo IV (parte I) del artículo "La nueva industria sonorense: el caso de las maquilas de exportación', que apareció en un libro compilado por el mismo autor y cuyo titulo es La nueva industrialización en Sonora: ei caso de los sectores de alta tecnología, Hermosillo, El Colegio de Sonora, 1988.

* Profesor-investigador visitante del Departamento de Estudios Económicos de El Colegio de la Frontera Norte.

1 Cfr. en especial José Carlos Ramírez, "Hipótesis acerca de la historia económica y demográfica de Sonora en el periodo contemporáneo" (Cuaderno del Viejo Pitic núm. 1), Hermosillo, El Colegio de Sonora, 1985.
} 
exportador (el centro de acumulación dominante en aquel entonces), sino también en aspectos importantes de la agricultura, el comercio, la banca e incluso la pesca. ${ }^{2}$ Una segunda etapa, que arranca con la crisis de las actividades exportadoras y que termina con la diversificación urbanoindustrial de los capitales agrarios nacionales (1930-1962), se caracterizó por presentar cambios radicales en las formas de propiedad extranjera. Durante este periodo los norteamericanos se limitaron a invertir en las filiales de sus empresas transnacionales (ET), a financiar proyectos agropecuarios y a monopolizar la compra de productos primarios, pero sin mantener el control directo de la anterior etapa. Su nuevo papel como figuras adscritas a la producción nacional obedeció a una compleja suma de causas nacionales e internacionales que hizo pedazos el viejo modelo mineropecuario exportador sobre el cual sustentaban hasta entonces su estrategia económica. ${ }^{3}$ Y finalmente se puede distinguir una tercera etapa (1963-1988), durante la cual las ET desarrollaron nuevas formas de articulación económica en torno a las industrias de alta tecnología del estado (las maquiladoras, la Ford y las grandes minas de cobre). Nos referimos a formas sutiles que, por su naturaleza independiente de las decisiones locales, permitieron a los capitalistas norteamericanos recuperar el viejo poder económico del primer periodo, pero ahora a través del monopolio de las manufacturas secundarias.

Nuestro interés en este documento se concentra en la última etapa porque, además de que ha sido poco estudiada, ${ }^{4}$ es la que condensa las formas económica y tecnológica más avanzadas de la inversión estadunidense en el estado. Es, por decirlo de alguna manera, cuando hacen época las transformaciones industriales más impresionantes de toda la historia económica sonorense.

Debido a ello el objetivo de este corto ensayo, el análisis del significado y naturaleza de la tercera etapa, es sólo una forma velada de reinterpretar el papel de los norteamericanos en la región entre 1890 y 1965, ya que de otro modo (esto es, sin hacer referencia a esos años), sería imposible detectar el carácter novedoso de su influencia en la estructura industrial y, en la sociedad sonorense como un todo. Además, el estudio de este periodo es el único camino seguro para estimar cuánto de la evolución económica de Sonora en el último siglo se debe a proyectos estadunidenses y cuánto de nacionales.

Dicho esto, conviene aclarar que decidimos tomar cómo sujetos de análisis sólo a las maquiladoras y a la Ford, porque el caso de las minas

2 Para más detalles cfr. Varios, Historia general de Sonora. Periodo contemporáneo 1929-1984, Hermosillo, Gobierno del Estado de Sonora, 1985, capítulo I.

3 Ibid., capítulos $1,3,4$ y 7 .

4 Al respecto puede consultarse José Carlos Ramírez, "La nueva industrialización...", en ibid., cap. 1 . 
de cobre supone comparaciones que escapan a los límites de este trabajo. En particular, estas últimas incluyen modalidades en el ciclo internacional del capital (concentradas en las etapas iniciales del proceso productivo - las de capital-) que difieren de la segmentación experimentada por las dos primeras en las últimas fases del proceso (o sea las intensivas en fuerza de trabajo); lo cual, como es de esperar, complejiza enormemente el análisis. Sin embargo, y en descarga de nuestra conciencia, remitimos al lector a otro trabajo donde ya hicimos esta comparación. ${ }^{5}$ Por razones de espacio, agrupamos el texto de la siguiente manera: dos puntos iniciales para llamar la atención sobre la naturaleza diferencial de la Ford y de las maquiladoras en relación a otras formas de inversión norteamericana, y dos puntos más para resumir los hallazgos de una investigación que realizamos acerca de la experiencia de ambos tipos de plantas en Sonora. ${ }^{6}$ En conjunto el trabajo cuenta con cuatro apartados para demostrar que la nueva presencia norteamericana en la entidad ha creado un segundo frente de reproducción, libre de cualquier influencia nacional importante. Veamos, pues, como enfrentar esta hipótesis.

Decíamos arriba que con el establecimiento de las plantas ensambladoras en la frontera norte, los capitales estadunidenses volvieron a Sonora como lo hicieron entre 1890 y 1930: sin intromisiones locales en la dirección del proyecto económico. Pero nos faltó aclarar que a diferencia de aquellos años en que los Green o los Richardson monopolizaron por completo la producción de las minas de cobre o de la agricultura de riego, los dueños de las maquiladoras asentaron su hegemonía sobre la base de un control ejercido en las últimas etapas del producto.

Lo anterior significa que mientras los antiguos monopolios ya desaparecidos (como la Cananea Consolidated Copper Co. o la Tiger Mining) necesitaron del acomodo físico de una planta fabril que llevara a cabo el beneficio del producto extraído aquí, de una banca propia que financiara sus actividades, o de la adquisición de un sistema independiente de transporte, las maquiladoras de la General Instrument en Nogales o de la Memorex en Magdalena, nunca precisaron más que gastos de operación indispensables para contratar una fuerza de trabajo nativa dispuesta a ensamblar productos transferidos del exterior. Y esto hizo (y hace) que los efectos generados en el estado por ambos tipos de inversión fueran (y

\footnotetext{
5 Ibid. y de la misma obra Óscar Contreras y Miguel A. Ramírez, "La nueva minería sonorense: historia reciente de una vieja industria", pp. 241-297.

${ }^{6}$ Ibid., cap. I.
} 
sean) distintos y a menudo sin ningún parangón, pues mientras que en el primer caso se requirió de una clase empresarial que dirigiera interna y directamente el proyecto, en el segundo bastó sólo la transferencia de un segmento de tecnología para relevar a los nuevos capitales transnacionales de todos los conflictos que asumieran sus antecesores.

Es por esta última cualidad que la industria maquiladora de exportación (IME) se convirtió en su momento en la forma más novedosa de valorización del capital extranjero y, quizá, en la que más autonomía ha alcanzado, desde entonces, respecto de cualquier fuerza interna. Su total subordinación a las políticas diseñadas por la matriz extranjera y el nulo contrapeso ejercido por los capitales locales en las ramas donde regularmente ella opera, han hecho de las plantas ensambladoras el núcleo de un frente de acumulación completamente independiente de los intereses agropecuarios. ${ }^{7}$ Con la IME los norteamericanos no sólo alteraron las reglas de intercambio mantenidas entre sus ET agroindustriales (que datan de los años cincuenta) y las actividades primarias de la entidad, sino que además lo hicieron sin cargar con los graves costos sociales del ancien regime (esto es del complejo minero exportador).

Teóricamente esta diferencia no es más que una distinta manera de interpretar la presencia del capital estadunidense en Sonora a lo largo de las tres etapas mencionadas. En primer lugar porque la internacionalización del ciclo del capital entre ellas no ha sido igual: en tanto que en las dos primeras etapas se llevó a cabo mediante la exportación de capital -dinero y mercancías - , en la tercera se dio a través de la escisión de un segmento del proceso productivo comandado desde afuera. Y en segundo lugar porque si bien es cierto que en las dos últimas etapas las ET buscaron comercializar a un bajo costo salarial, la estrategia fue distinta: mientras que en la segunda trasladaron completamente a la filial para beneficiar los insumos nacionales, en la tercera lo hicieron, repitámoslo, por intermedio de la maquila de artículos semiprocesados provenientes del exterior.

Esta naturaleza distintiva del capital maquilador vino a romper con un esquema de industrialización caracterizado por absorber hasta $50 \%$ de su valor en materias primas procedentes de las unidades agropecuarias. ${ }^{8}$ Su escasa integración nacional (consume apenas 1\% de su valor agregado

7 Véase José Carlos Ramírez, op.cit., pp. 23-30.

${ }^{8}$ Este esquema de industrialización, que ha caracterizado a las manufacturas sonorenses desde hace casi cuarenta años, se distingue por integrar dos sistemas agroindustriales: el del trigo y el del algodón. Mientras el primero incorpora activamente a los agricultores con los grupos nacionales productores de alimentos (a través de las uniones de crédito), en el segundo los grandes productores actúan como simples intermediarios de las ET, tal como sucede con las empresas beneficiadoras de ajonjolí y cártamo (Anderson Clayton por ejemplo). En ambos casos los agricultores mantienen el control total de las fases productivas previas a su transformación (agroquímica y aperos agrícolas) y sólo en muy pocos casos, como en la elabo- 
en insumos locales) provocó que las manufacturas estatales dejaran de ser la habitual prolongación de la economía primaria (sobre todo de las empresas adscritas a las Uniones de Crédito) para convertirse en el elemento desconcentrador por excelencia de la actividad económica después de 1970. La peculiar distribución espacial de la IME le otorgó a ciudades como Nogales y Agua Prieta tal preeminencia en ciertas líneas productivas que hubiera sido imposible llevar a cabo bajo el predominio de las actividades primarias.

Esto es importante destacarlo porque antes de la instalación de esas plantas, aquellas cabeceras no eran más que centros de tráfico comercial entre los Estados Unidos y los valles agrícolas - y los minerales-, es decir sólo formaban parte de una extensa cadena de procesos económicos gobernados por la producción agropecuaria de la Costa. En cambio, cuando en la frontera de México con los Estados Unidos se empezaron a expandir las empresas norteamericanas de partes eléctricas, electrónicas y automotrices, todos esos lugares se transformaron de pronto en sedes de proyectos fabriles tan avanzados para las manufacturas locales que los extranjeros terminaron incubando allí una zona económica independiente.

Por eso en Sonora, como en todos los estados fronterizos del norte de México que no se habían industrializado bajo la estrategia de sustitución de importaciones, el pasaje de una economía agrícola a otra de corte más secundario fue sumamente drástico y diferente al esquema clásico de desarrollo, debido a que ahí la maquila, lejos de integrar el espacio de valorización dominante (el agropecuario), lo fragmentó en dos entidades paralelas. Además, mostró a su clase empresarial las cortas posibilidades de crecimiento en esa sección de la manufactura y, al igual que en la actual minería de cobre, le concedió apenas el dramático papel de espectador. ${ }^{9}$

Sólo la Ford en Hermosillo presenta características similares a la maquila, pues fuera de ella no hay en la entidad ninguna otra empresa nacida de la segmentación internacional del proceso productivo. Juntas forman la célula de la nueva industrialización en Sonora, que ha convertido las manufacturas secundarias del estado en un apéndice de la actividad transnacional. Además, sobre ambas se erigen los proyectos de "reconversión industrial" más ambiciosos que jamás se hallan visto en la entidad y por lo mismo los que más han acentuado el poco desarrollo tecnológico logrado por las ramas tradicionales de la transformación. En suma: sin las maquilas y la Ford las líneas de partes eléctricas, electrónicas y automotrices del estado serían inexistentes.

ración de pastas, han logrado cierta integración productiva “hacia adelante". Cfr. Gustavo Gordillo, Los campesinos al asalto del cielo, México, Siglo XXI, 1988.

9 Véase Óscar Contreras y Miguel A. Ramírez, "La nueva minería...", op. cit., pp. 257 y 258 . 
En ese sentido las maquilas y la Ford no sólo han "separado" la frontera de los valles, sino que también han dividido la especialización industrial de los nacionales y los extranjeros en su interior. De esto da prueba el desproporcionado crecimiento de las empresas secundarias ligadas al capital extranjero en relación con el experimentado en estas ramas por los grupos económicos nativos. Sólo en el caso de la Ford se tiene que de las 27 empresas colaterales próximas a establecerse, la mayoría son de capital foráneo y juntas representan casi el total de establecimientos previstos para crearse en el parque industrial de Hermosillo en ese lapso. Otro tanto ocurre en Imuris, San Luis Río Colorado y Empalme, donde los recientes avisos de inversión son de capital maquilador. ${ }^{10}$

Debido a esto, la llamada nueva industrialización sonorense no es un proyecto nacional, y a diferencia de lo que creen sus promotores, su permanencia en el territorio no es indefinida, pues responde a cambios internacionales que estudiaremos a continuación. Así que la división económica que ahora observamos podría desaparecer si ciertos factores favorables se esfuman, porque ni siquiera los robots o el equipo más computarizado del país (aplicados por la Ford) pueden asegurarnos que a la vuelta de la esquina la industria local no vuelva a ser otra vez sólo de corte primario.

II

Sin embargo, no hay que considerar que la planta Ford y las maquilas son iguales, puesto que cada una presenta peculiaridades difíciles de pasar por alto. Una de ellas tiene que ver con su modalidad de operación en el territorio de destino, y en concreto con el hecho de que mientras

la maquila actúa bajo una modalidad particular en condiciones de excepción (...) como actividad propia de la transnacional correspondiente (...) la Ford... funciona bajo una modalidad general en condiciones regulares o normales, al igual que otras empresas diseminadas en el conjunto del aparato productivo; con una legislación propia que no comparte del todo los rasgos de (las maquiladoras). ${ }^{11}$

Igualmente, y como segunda peculiaridad, tenemos que la Ford y las maquiladoras presentan diferencias en las causas de su emplazamiento, que conviene analizar con cuidado. Para empezar, diremos que aun cuan-

10 Véase José Carlos Ramírez, "La nueva industrialización...", op. cit., p. 31.

11 Sergio Sandoval Godoy, "Los enlaces económicos y políticos de la Ford Motor Co. en Hermosillo. Internacionalización productiva y nuevas tecnologías en Varios, Historia general..., parte I, p. 166. 
do ambas vienen atraídas por el bajo costo de la fuerza de trabajo, ${ }^{12}$ no es sensato atribuirle el mismo significado en los dos casos. Y la razón es que mientras para la Ford este ahorro representa una parte de su estrategia reproductiva en Sonora, para las maquiladoras es casi la totalidad (80\% de sus gastos de operación).

La instalación de la Ford cristalizó gracias a un convenio japonésestadunidense para que tanto ella como la Toyo Kogyo pudiesen penetrar en el mercado conjuntamente y no en forma anónima como en las plantas ensambladoras. La asociación en este caso fue un mecanismo para dividir oligopólicamente el mercado de autos compactos (no sólo para abrir nuevos segmentos), pues además de bajar los costos del producto a través del reforzamiento e intercambio tecnológicos, representó una manera de refinar la competencia para no verse desplazadas por otras empresas asociadas (por ejemplo General Motors y Toyota). La Ford pretende disminuir mediante el convenio las perdidas derivadas del bajo nivel de ventas (1 000 millones de dólares en 1980-1982) aportando $24.5 \%$ del capital y cerca de 600000 motores, además de transmisiones y otros componentes importados de Estados Unidos.

Por eso su planta de ensamblado y estampado (que planea producir 130000 unidades por año) se ve urgida de valorizar la mayor cantidad posible de fuerza de trabajo compleja —esto es calificada, y con equipo tecnológicamente sofisticado- y no simple como en las maquiladoras. Antes que evitar el alargamiento de la jornada de trabajo (tan necesaria para el funcionamiento de las maquilas), necesita de una amplia infraestructura en transporte y servicio que le permita expandir su producción a gran escala. Su estabilidad en Sonora depende más de aquellos factores que están ligados con la adecuada utilización de su elevadísima composición técnica de capital, ${ }^{13}$ que con el sistema de rotación de eventuales o de cuotas como en las demás plantas.

Estas diferencias explican a su vez por qué los cambios en las tecnologías de procesos, en la telemática, en los sistemas organizativos (entregas "justo a tiempo", círculos de calidad, etc.) y en los demás elementos que regularmente han sido consagrados como factores clave del movimiento de las empresas, operan con distintos resultados en la Ford y en las maquiladoras. ${ }^{14}$ Por ejemplo, para la Ford la aplicación de la robótica

12 En Sonora esta diferencia oscila entre 7 y 12 veces menos el salario del "Frost Belt", Arizona y California, sus principales suministradores de maquila. Si consideramos a la Ford, la diferencia sería del orden de 30 veces menos comparada con lo que se le paga a un obrero manufacturero en Detroit.

${ }^{13}$ De hecho una de las ventajas que vio la Ford al desplazarse de California a Hermosillo fue el mayor número de robots que podía incorporar sin enfrentar problemas sindicales como en su lugar de origen. Un robot sustituye en promedio a 6.3 hombres.

14 En general se reconocen cuatro grupos de causas que explican la exportación de segmentos productivos a los países de bajos salarios relativos (además, obviamente, de la búsque- 
-tecnología flexible- es uno de los factores clave que, junto con la "japonización" de las relaciones laborales y sindicales, han favorecido más su estabilidad. En cambio, en las maquiladoras la situación es diferente, ya que con excepción de las empresas grandes (500 trabajadores o más), las transformaciones tecnológicas han hecho quebrar las matrices de las empresas pequeñas, o en su defecto, las han obligado a replegarse en su país de origen tras la automatización completa de su proceso productivo (como sucedió con Motorola en 1985).

De la misma manera, la fusión de empresas transnacionales es un fenómeno que ha tendido a alentar la "maquilización" de la industria automotriz, y a inhibir la permanencia de ciertas plantas ensambladoras en la frontera norte. La razón es que la expansión del sector terminal de la Ford fuera de Estados Unidos estuvo precedida por la participación de otros capitales. Sin los acuerdos de cooperación con otras corporaciones, la Ford se hubiera visto, seguramente, imposibilitada para abatir sus costos y, en consecuencia, para acceder al mercado japonés y norteamericano de autos compactos. En las maquiladoras, por el contrario, los efectos de la fusión han sido más bien ambiguos pues, por un lado, han favorecido la aparición de empresas auspiciadas por los ministerios de algunos países, que son poseedoras de la última innovación (como por ejemplo del semiconductor VLSI o VHSI), y por otro lado han tendido a desalentar los servicios de maquila bélica por planes de seguridad militar, por la claúsula del second source o por especificidades mayores en el producto. En una palabra: la fusión ha puesto a la maquila entre dos fuerzas igualmente dominantes y con sentido contrario. Así que no hay que olvidar que la permanencia de la maquila depende de qué fuerza domine y, en especial, del grado de saturación en el mercado internacional y de la relación de costos (en la maquinaria y equipo) y ganancias (por la maquila). Mientras tanto ya se ha empezado a observar en Sonora una mayor afluencia de empresas provenientes de California (centro de empresas fusionadas).

Como última peculiaridad que importa distinguir es el tipo de lazos que ambas industrias mantienen con el gobierno y los empresarios nacionales. Mientras con la Ford la interacción es modesta pero persistente, con las maquiladoras es prácticamente nula. La maquila en Nogales (la principal plaza de Sonora) es controlada en todas sus fases por estadunidenses: desde la contratación de plantas hasta su funcionamiento en el par-

da de mayores tasas de ganancia por parte de las ET); a saber: el desarrollo de la telemática; la estandarización de la tecnología de procesos; los factores económIcos relacionados con la maduracIón del producto (estructura de demanda y costos) y los elementos InstitucIonales (aranceles, subsidios gubernamentales, etc.). La explicación de cada uno de ellos así como su grado de Influencia en una plaza fronteriza (Nogales, Son.) se encuentran en José Carlos Ramírez, op. cit., caps. II y III. 
que industrial. Los empresarios nacionales son tan extraños ahí que un poco más de $85 \%$ de los gerentes son estadunidenses. ${ }^{15}$

Esto no quiere decir, obviamente, que con la Ford exista una mayor reciprocidad, pues para ello hay que poner en la balanza los $1200 \mathrm{em}$ pleos y los 200 millones de dólares que generan, contra los gastos hechos por el gobierno federal en el gasoducto Naco-Cananea-Hermosillo (3 800 millones de pesos a precios de 1984), el préstamo de 20000 millones de $\operatorname{pesos}^{16} \mathrm{y}$ todas las garantías, exenciones y fuerza de trabajo que se le han ofrecido. Lo único que significa es que la incorporación que hace de proveedores nacionales es importante, y que los efectos multiplicadores que ello genera exigen una mayor interrelación.

Esto coloca a la Ford como líder del sector (industrial secundario), incluso sobre la maquila, condicionando el desarrollo de otras actividades importantes ligadas con ella. Es el caso de Carplastic, que requirió de una inversión de 600 millones de pesos para la producción de tableros y defensas para la Ford; Central de Industrias, 4420 millones para producir asientos; Good Year Oxo, $260 \mathrm{mi}$ llones para producir rines y llantas; Cima, 473.2 millones para alfombras moldeadas; PEMSA, 481 para producir cinturones de seguridad; Aurolinm, 676 y Pittsburg 100 millones. La Ford influye sobre sus prioridades estrátegicas durante cada fase del ciclo para que pongan en práctica su capacidad organizativa, las posibilidades tecnológicas e innovadoras y las necesidades de mano de obra. De la misma manera influye en las decisiones sobre localización de otras empresas y las respuestas de organización frente a los asuntos laborales y las relaciones de mercado. 17

Sin embargo, la naturaleza de la Ford la hace tan autónoma de cualquier tipo de producción local que no es posible decir que se encuentra sometida a un proyecto nacional. En esto se asemeja a las maquiladoras.

\section{III}

A pesar de estas diferencias, la Ford y las maquiladoras tienen en común ser las empresas mas dinámicas de la economía sonorense, no sólo en em-

15 Sobre la estrategia desarrollada por la Asociación de Plantas de Ensambles en Nogales, consistente en aceptar únicamente maquila estadunidense, véase Vania Muller, "Las condiciones socioeconómicas del trabajo en las maquiladoras desde la perspectiva de la investigación directa". México, 1975, mimeo.

16 Este crédito fue otorgado en 1984 por el Banco Nacional de México, el Banco de Comercio y otras instituciones financieras del país. "El préstamo pactado a un plazo de siete años, con tres de gracia, representa la quinta parte aproximadamente de la inversión total calculada (ese año) en 100000 millones de pesos. La dimensión del prestamo nos da las (siguientes) comparaciones aritméticas: los 20000 millones de pesos (son) casi igual al presupuesto de egresos de Sonora para 1984 ... que fue de 23028.5 millones de pesos, y equivalente al total de la inversión pública federal para el estado en ese año", Miguel Ángel Vázquez. "Los grupos de poder económico en Sonora", Departamento de Economía, Unison, Hermosillo, 1988, mimeo.

17 Véase Sergio Sandoval Godoy, op. cit., p.168. 
pieos sino también en divisas. Las 110 maquiladoras junto a la docena de plantas periféricas a la Ford (incluyendo a ésta) aportan cerca de $50 \%$ del empleo manufacturero y un porcentaje algo mayor en divisas estatales. Sus 300 millones de dólares no son ni siquiera superados por el camarón y los productos agropecuarios juntos, que eran los artículos tradicionalmente líderes del comercio exterior estatal. Y esto las ha colocado como las industrias que han crecido más, junto con la minería y la construcción. Cálculos provisionales estiman que su valor agregado en 1987 osciló entre el 35 y $40 \%$ del PiB industrial, lo cual habla de su impresionante tendencia si consideramos que apenas dos años atrás este porcentaje no rebasaba 25 por ciento.

Por si esto fuera poco, estas plantas fueron responsables de las altas tasas de crecimiento observadas por el sector secundario entre 1975 y 1986 tanto en el número de establecimientos como en sus coeficientes de densidad de capital e ingreso promedio. De esto es fácil convencerse si tenemos en cuenta: a) que tanto la Ford como las maquiladoras crecieron a tal ritmo que casi triplicaron el número de empresas de bienes de capital durante este periodo, aportando $57 \%$ del incremento registrado por las manufacturas; b) que la inversión registrada por la Ford (y sus satélites) entre 1984 y 1988 ascendió a 750 millones de dólares, cantidad que dividida por sus 1000 trabajadores dio un promedio de 750000 dólares de capital por irabajador; algo desproporcionado para el medio local, si se considera que en sus líneas más importantes (bienes de consumo no duradero) esta cifra apenas alcanzó los 15 dólares por trabajador, y finalmente c) que gran parte $(80 \%)$ del valor agregado por las plantas ensambladoras (Ford y maquiladoras) en este año fue destinado al pago salarial, lo que arrojó un promedio de 10000 dólares de divisas por empleado al año o sea casi 200 veces el ingreso de un obrero de las industrias tradicionales. ${ }^{18}$

Pero, como en todo proceso económico, la historia de estas cifras no siempre fue lineal ni rosada: incluyó también repercusiones sociales que no es posible pasar por alto. Por eso, para tener una idea completa del significado de estas empresas, conviene analizar su tendencia en el tiempo. Y para ello recurriremos a la experiencia de la maquila, porque solo ella nos ofrece una visión de largo plazo que no es posible apreciar en la Ford. ${ }^{19}$

18 Varios, "Subsistema de ciudades Hermosillo-Nogales-Cd.Obregón”, Hermosillo, El Colegio de Sonora, 1988, mimeo. El promedio se calculó sobre la base de 250 millones de dólares pagados a los obreros y de 25000 trabajadores existentes en ambas plantas (durante el periodo 1986-1987). La comparación fue hecha convirtiendo al tipo de cambio vigente en diciembre de 1986, el valor agregado de las industrias de alimentos, bebidas y textiles.

19 Para el caso de la huelga ocurrida en la Ford y otros "costos sociales" inherentes a su funcionamiento, véase el capítulo 3 y las conclusiones del trabajo de Sergio Sandoval Godoy ya citado. 
Los establecimientos y su concentración

A estas alturas es casi una repetición señalar que alrededor de $95 \%$ de los establecimientos ubicados en Sonora son filiales de ET estadunidenses dedicadas principalmente al ensamble de productos eléctricoelectrónicos (46.1\%) y de manufacturas diversas (véase cuadro 1). Se trata de empresas provenientes en su mayoría del norte-centro, noreste y California, previamente afincadas en Arizona (véase el mapa 1), cuyas dimensiones son constrastantes entre sí y el medio local por dos razones: porque a pesar de poseer un capital contable similar al registrado por las empresas pequeñas o medianas nacionales, ocupan en promedio a más hombres y mayor capital fijo que cualquier planta de Sonora ${ }^{20}$ y porque la concentración entre ellas es realmente notoria, pues sólo en Nogales las 10 empresas más grandes (19.3\% del total) agruparon en 1985-1986, $54 \%$ de la fuerza de trabajo ahí ocupada.

Estos hechos no serían significativos, sobre todo los referentes a la procedencia de las empresas, si no fuera porque a nivel nacional los estadunidenses controlan sólo $56 \%$ de los establecimientos maquileros y un monto similar en el capital social (52\%), es decir un porcentaje apenas superior a las empresas de participación nacional $(41 \%)$. A reserva de profundizar en esto más adelante, diremos que esta situación se debe a la es-

CUADRO 1

Participación de la industria maquiladora por rama de actividad económica (1986-1987)

\begin{tabular}{lr}
\hline \multicolumn{1}{c}{ Rama } & \% del total \\
\hline Materiales y accesorios eléctricos y elec- & 42.30 \\
trónicos & 21.08 \\
Manufacturas diversas & 7.70 \\
Maquinaria, equipo de transporte & 7.70 \\
Muebles, partes y otros de madera y metal & 6.40 \\
Cuero y calzado & 5.20 \\
Prendas de vestir y otros productos textiles & 3.80 \\
Maquinaria, herramienta y equipo no eléctrico & 3.80 \\
Equipo y accesorios eléctricos y electrónicos & 1.30 \\
Servicios & 100.00 \\
Total & \\
\hline
\end{tabular}

Fuente: Subsecretaría de Fomento Industrial del Estado de Sonora.

20 El monto promedio de cualquier maquiladora mediana en Nogales asciende a 15000000 de capital contable (sin incluir capital fijo) y su número de empleados alcanza en promedio 300 obreros. En las electrónicas grandes este número rebaja los 750 trabajadores. 


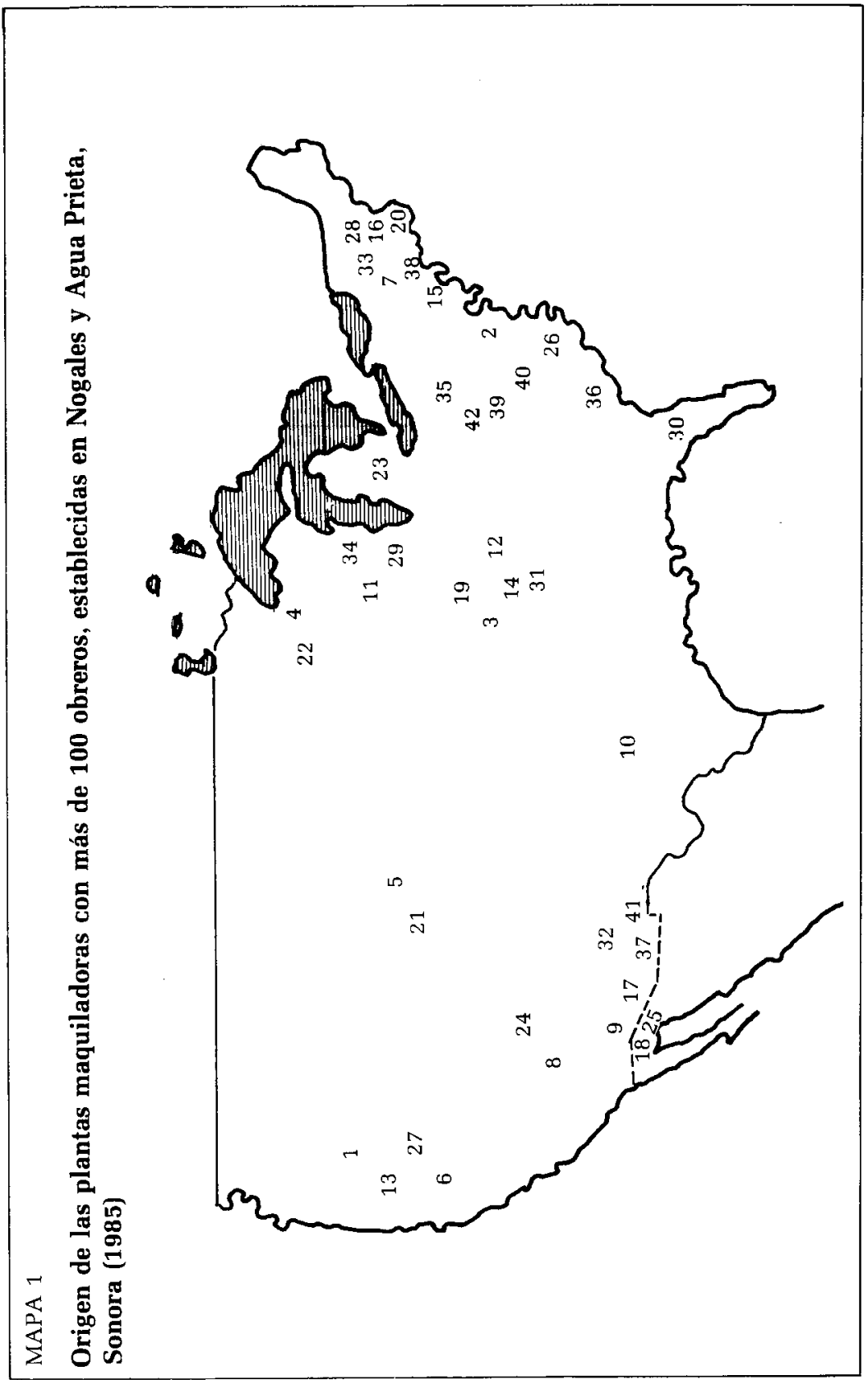




\section{Lista de plantas maquiladoras con más de 100 empleados}

\begin{tabular}{|c|c|c|}
\hline Lugar: Nogales, Sonora & $\begin{array}{c}\text { Núm. de } \\
\text { empleados }\end{array}$ & Manufactura \\
\hline 1 Mem-Mex & 1695 & Arneses de alambre \\
\hline 2 General Instrument de México & 1407 & Componentes eléctricos \\
\hline 3 Perma-Mex & 1335 & Sistemas de seguridad \\
\hline 4 Avent & 1083 & Productos médicos \\
\hline 5 Sam-Son & 960 & Equipajes \\
\hline 6 West-Cap Arizona de México & 841 & Productos electrónicos \\
\hline 7 Jeffel de México & 727 & Inductores \\
\hline 8 Hasta-Mex & 630 & Circuitos impresos y arneses \\
\hline 9 Tecnología Mexicana & 590 & Capacitaciones de cerámica \\
\hline 10 Rockwell, Collins de Nogales & 551 & Componentes electrónicos \\
\hline 11 Circuitos Mexicanos de Nogales & 532 & Arneses de alambre \\
\hline 12 Molex & 502 & Switches y conectores \\
\hline 13 Shugart de Nogales & 383 & Discos para computadoras \\
\hline 14 Productos de Control & 380 & Componentes electrónicos \\
\hline 15 Magnetic Metals & 310 & Componentes electrónicos \\
\hline 16 Sistemas y conexiones int. & 306 & Cable para computadoras \\
\hline 17 Manufacturas ind. de Nogales & 302 & Ropa \\
\hline 18 Charles E. Gillman & 301 & Arneses de alambre \\
\hline 19 Lowrey de México & 263 & Partes eléctricas para órganos \\
\hline 20 Foster Grant Mexicana & 250 & Lentes para el sol \\
\hline 21 Deseret & 235 & Productos para hospitales \\
\hline 22 Wortronics & 234 & Partes de computadoras \\
\hline 23 Walbro de México & 233 & Carburadores \\
\hline 24 Ingeniería Aplicada & 190 & Filtros para radio \\
\hline 25 Cambion de México & 188 & Componentes electrónicos \\
\hline 26 Bal-Mex & 197 & Ropa interior \\
\hline 27 El Cid & 180 & Conectores electrónicos \\
\hline 28 Delmed & 178 & Productos para hospitales \\
\hline 29 Badger Meter de México & 147 & Medidores para fluidos \\
\hline 30 Magnetics Electrónica & 110 & Inductores y bobinas \\
\hline \multicolumn{3}{|l|}{ Lugar: Agua Prieta, Sonora } \\
\hline 31 Equipo Automotriz Americano & 800 & Cinturones de seguridad \\
\hline 32 Telson de México & 800 & Componentes de televisión \\
\hline 33 Rogers Mexicana & 672 & Componentes de computadoras \\
\hline 34 Hamlin & 516 & Switches y relays \\
\hline 35 Industrias Apson & 500 & Ropa y productos paramédicos \\
\hline 36 Camisas Bahía Kino & 389 & Ropa \\
\hline 37 Intermex de Sonora & 385 & Ensamblados y servicios \\
\hline 38 Unitrode Mexicana & 330 & Rectificadores electrónicos \\
\hline 39 Underwood Electric Division & 300 & Productos electrónicos \\
\hline 40 SI de México & 261 & Productos electrónicos \\
\hline 41 Sonidos Selectos de Sonora & 250 & Ensambles de equipo de sonido \\
\hline 42 Com. General Mexicana & 121 & Detectores de radar \\
\hline
\end{tabular}

Fuente: Asociación de Plantas Ensambladoras de Nogales y Agua Prieta, reproducido por Arizona Daily Star, febrero de 1985, Tucson. 
casa presencia de la maquila textil y de muebles en el estado, que es donde precisamente se ubican los capitalistas nacionales, y a la decidida estrategia de los gobiernos de Félix Serna y de Biebrich (1967-1975) de privilegiar la de origen eléctrica-electrónica (en otras palabras la estadunidense).

A hora bien, vistas a lo largo de 24 años las plantas ensambladoras presentaron dos importantes quiebres en su crecimiento durante la crisis de 1975-1977 y 1982 (véase la gráfica 1), y ambos por razones de orden internacional. ${ }^{21}$ Salvo esos dos picos, la tendencia general marca una trayectoria ascendente e incluso a establecerse por encima de las 100 maquiladoras (10\% del totäl nacional, si contamos como plantas los "departamentos de producción" de la empresa contratista Sonitronies).

El rasgo sobresaliente de este crecimiento es su casi total concentración en dos ciudades: Nogales y Agua Prieta, ya que pese a que el porcentaje disminuyó en los últimos años (de $98 \%$ en 1970 a $74 \%$ en 1988), la proporción mantenida por ambas cabeceras nunca dejó de ser determinante en el rumbo de la maquila estatal (véase la gráfica 2). Sobre ellas se ha erigido la historia de esas plantas en Sonora, ya que ahí se han localizado las empresas más grandes, las que han generado más empleos y divisas y donde se han registrado las mayores consecuencias sociales del fenómeno.

Nogales ha sido el epicentro de los grandes cambios. ${ }^{22}$ Ahí fue donde se dio el mayor impulso al Programa Nacional Fronterizo (y más tarde al Programa de Industrialización Fronteriza, PIF), donde se cristalizó el establecimiento de la primera maquila en 1963 (por efectos de la Ley de Fomento Industrial de 1962 o Ley 16) y, algunos años después, de los tres grandes consorcios pioneros de la segmentación internacional del proceso productivo (Motorola, Packard Bell y Fairchild Semiconductors). En pocas palabras, fue la sede del primer proyecto industrializador no primario en Sonora, puesto en marcha bajo el plan de diez años de Luis Encinas (1961-1967) y más tarde reforzado por el gobierno de Félix Serna mediante la aplicación de la Ley 49 de Fomento Indusirial, emitida en 1969.

A diferencia de Agua Prieta, Nogales tuvo en su haber el desarrollo precoz de un parque industrial (diseñado y construido por la ET "Arthur Little Co.") y el eficiente servicio de una compañía contratista estaduni-

21 Tanto en 1975 como en 1982 el cierre de empresas se debió a la competencia,ejercida por las empresas japonesas y a la caída del precio de los semiconductores. Ambas razones terminaron por minar la poca competitividad de algunas empresas electrónicas, que no se adaptaron a las innovaciones tecnológicas en ciertos productos (como tocadiscos, relojes de cuarzo, monitores, etc.). Sobre esto véase United Nations, Conference in Trade and Development, Nueva York, ONU, 1978 y Cesáreo Morales, "El comienzo de una nueva etapa de las relaciones económicas entre México y Estados Unidos", en Pablo González Casanova (ed.), México ante la crisis (1), México, Siglo XXI, 1987, pp. 64-83.

22 Cabe destacar que entre 1984 y 1986 esta frontera agrupó $56 \%$ del total de empresas maquiladoras del estado y $62 \%$ del personal ocupado; además generó $74 \%$ de las divisas y el mismo porcentaje en salarios. 


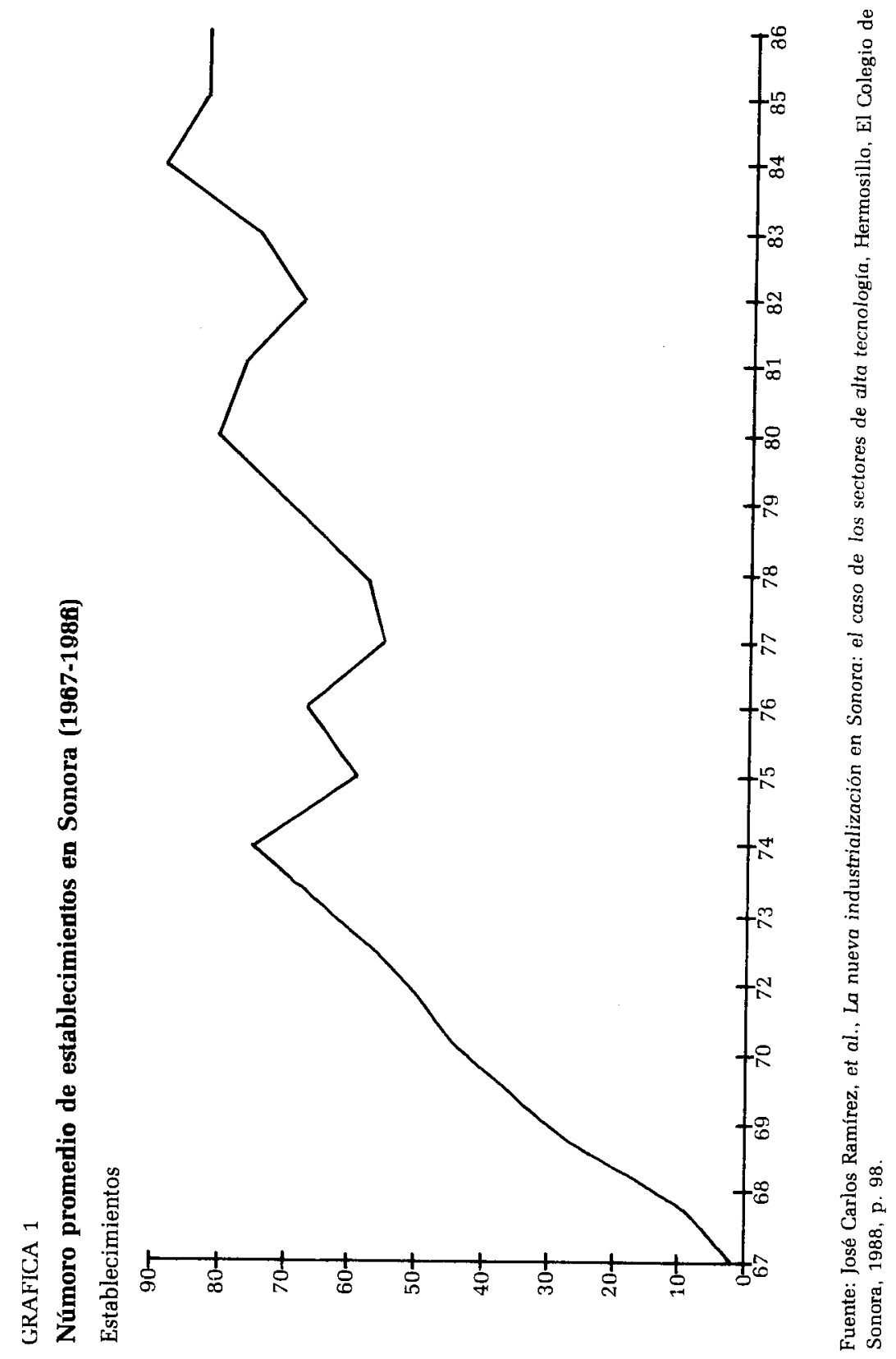




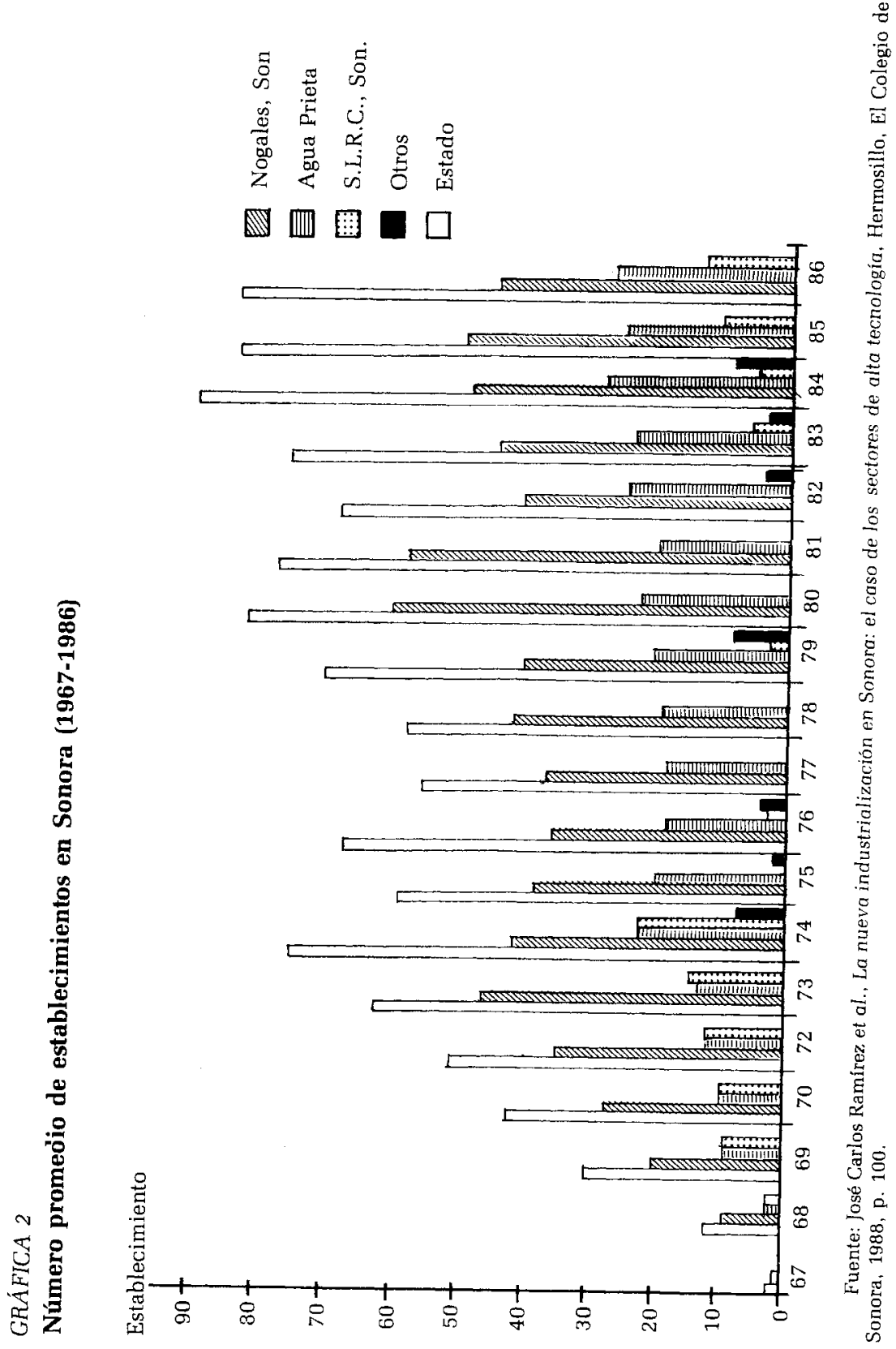


dense que hizo posible la internación a Sonora de empresas provenientes de Japón y Arizona. Esto explica, en parte, el mayor auge de las maquilas eléctricas-electrónicas en esta frontera, pero también su mayor caída durante la crisis de 1974-1977, pues al constreñirse el mercado electrónico estadunidense, Nogales no volvió a recuperar su nivel sino hasta cinco años después. Entonces las grandes empresas que tenían en su haber más de un desplazamiento previo (como la Motorola y la Packard Bell) terminaron por irse a Guadalajara o Taiwan, en tanto que las pequeñas quebraron junto con su matriz. Por su parte Agua Prieta siguió una suerte distinta, porque a pesar de recibir los impactos de la crisis, el gobierno y los comités promotores pudieron fortalecer el convenio de multifibras entre Estados Unidos y México y así sacar a flote la situación.

Las bajas registradas en la demanda internacional entre 1980 y 1983 siguieron afectando a las empresas eléctricas y electrónicas de Nogales de una manera intensa, pero ahora con menores efectos negativos sobre la actividad estatal. Y esto fue debido principalmente a la diversificación de empresas manufactureras no electrónicas en lugares tradicionalmente agrícolas como Hermosillo (a raíz de la instalación de la Ford) y Obregón (que inició la actividad de la maquila en noviembre de 1986 con una empresa automotriziz). (Véase la gráfica 2.)

La estabilidad de las empresas

Otro factor que desde 1974 ha contrarrestado la historia de cierres y aperturas, tan característica de estas industrias, es la estabilidad mostrada por algunas empresas que iniciaron sus actividades desde 1968. Entre ellas destacan la General Instrument, Mem-Mex, Perma-Mex, Avent y Sam-Son, que aún en la actualidad siguen siendo la columna vertebral de la maquila de Sonora, pues tan sólo entre 1985 y 1986 lograron ocupar $42 \%$ de la población trabajadora de Nogales y producir $35 \%$ de las divisas.

Su resistencia a los embates de 1974 y 1982 fue debido, principalmente, a la demanda inelástica de sus productos (Perma-Mex tuvo como comprador cautivo a Sears), a la posición de liderazgo en el mercado norteamericano de ciertas líneas (como Semiconductores en el caso de Gi) y a otras razones que tienen que ver con factores tecnológicos que desaceleran la "maduración del producto" (por ejemplo los artículos Top Secret solicitados por la Secretaria de la Defensa de Estados Unidos). En cualquier, caso las empresas arriba mencionadas pudieron elevar su ritmo de contratación y compensar la pérdida de fuerza de trabajo experimentada por otras empresas en los años más duros de la crisis. ${ }^{23}$

23 Entre 1980 y 1986 se observaron, según datos de las listas pre-elaboradas por la Secofi de Nogales, 14 aperturas, 16 cierres, 17 apariciones, 7 desapariciones, 6 permisos y suspensiones ( 2 cierres, 3 despariciones y 1 reapertura) 1 reaparición, 1 registro nuevo como empresa y 7 cambios de rama. De los cierres anunciados en Nogales, la mayoría se dio entre 1980 
Cifras 'oficiales (empleos y valor agregado)

Como consecuencia de los movimientos experimentados por las plantas, el empleo y las divisas siguieron también un curso errático entre 19741979 y 1981-1983. En particular, durante los primeros meses de 1975 la baja fue tan sensible que casi una tercera parte de los trabajadores quedaron sin empleo (véanse las gráficas 3 y 4), a la vez que el valor agregado cayó a niveles tan bajos que no pudieron recuperarse sino hasta 1978.

Con excepción de esos años el crecimiento en ambos rubros fue sostenido y casi sin parangón dentro de las manufacturas. Distintas fuentes de información, entre ellas un censo levantado por la anterior ad ministración de la Secofi estatal, revelan que el peso de la maquila en las manufacturas es tan significativo que a nivel de cuatro dígitos de la clasificación industrial (CMAP) no hay nada en Sonora que se le compare en generación de empleos y divisas (nos referimos a tasas de crecimiento) ${ }^{24}$

Características y condiciones de la fuerza de trabajo: resultados de encuestas

Uno de los rasgos sobresalientes de la fuerza de trabajo empleada en la iME de Sonora, es la creciente y progresiva incorporación de hombres en el proceso productivo. Algunas cifras muestran que esta proporción aumentó de 63 varones por cada 100 mujeres en 1975 a 70 en 1988, lo que significa en los dos casos más de dos veces el promedio nacional. Entre las razones de peso que explican semejante comportamiento destacan la creciente internación de plantas clasificadas como "manufacturas diversas", que se distinguen por su mayor demanda de fuerza muscular, y la escasez de mujeres en el ensamble de productos electrónicos.

Ambas razones han privilegiado desde 1975 la presencia de más hombres en las principales industrias de Nogales y una acelerada rotación de mujeres en los puestos de casi todas las plantas. A decir de la mayoría de los gerentes entrevistados, la permanencia promedio de los operarios de línea va de uno a tres meses (o de tres a seis en otras) y es debido principalmente a la competencia que ejercen otros empleos similares, al cambio de residencia y de estatus marital, y a los problemas de vivienda que

\footnotetext{
y 1984 afectando, como ya dijimos, a empresas electrónicas como la Temua Audio (que despidió a mil operarios en abril de 1981), que no resistieron la competencia japonesa en el ramo (tocadiscos). Dos empresas del mismo giro quebraron en Agua Prieta en enero de 1982 (Agua Prieta Electrónica y Ana-Mex). Sólo las grandes empresas (a excepción de la Samson, que despidió a 75 trabajadores en noviembre de 1981), pudieron expandirse: por ejemplo la Gr pasó de emplear a 600 trabajadores en 1979 a 1940 en 1980 y más de 2100 en 1982.

24 Primera Encuesta General de Industria elaborada por la Subdirección de Estadística con base en la Clasificación Mexicana de Actividades Económicas y Productivas (CMAP). Por diversos motivos no fue posible llenar ni tabular la información en forma completa, debido a lo cual nos remitimos a las hojas de vaciado.
} 


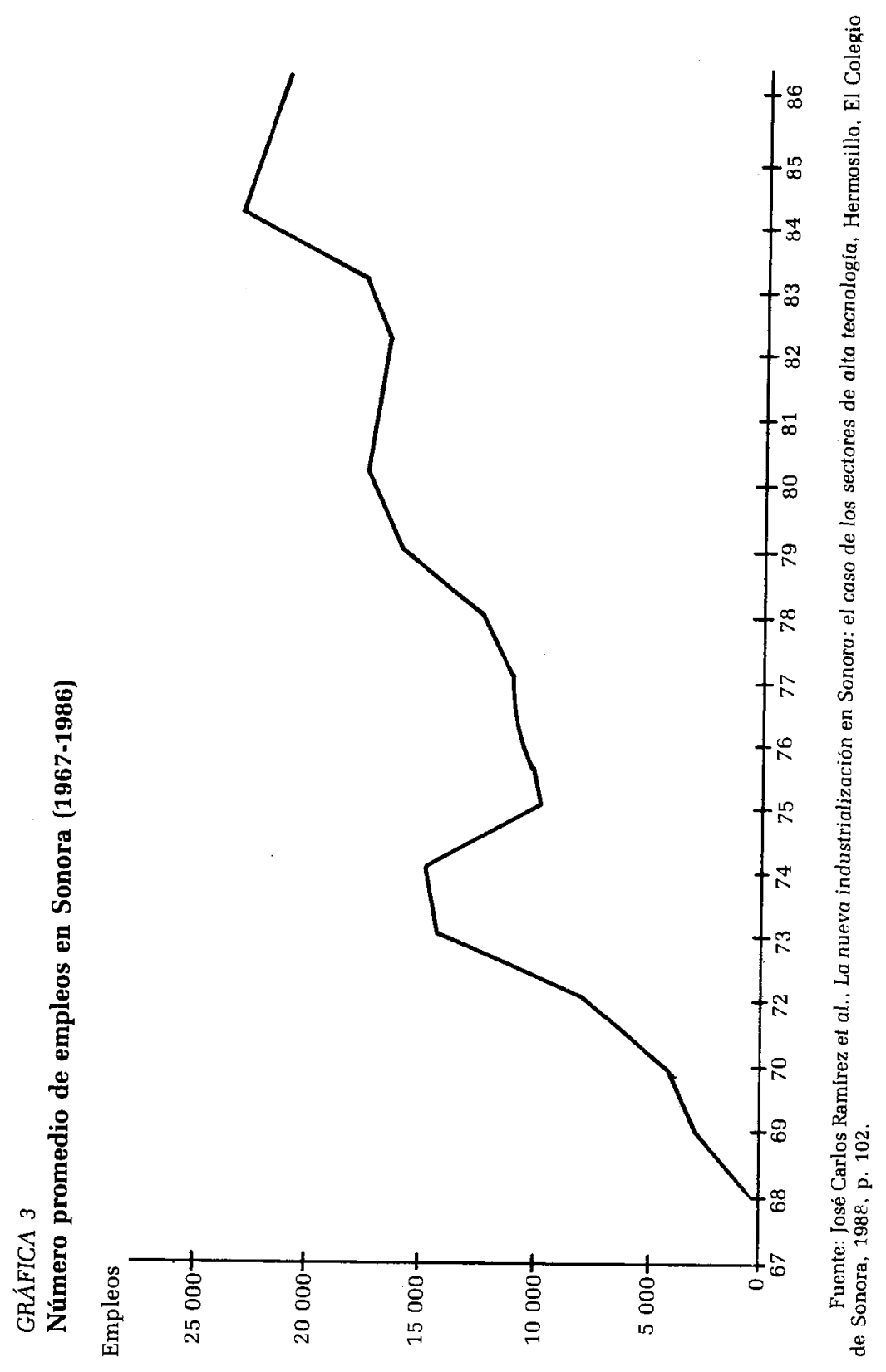




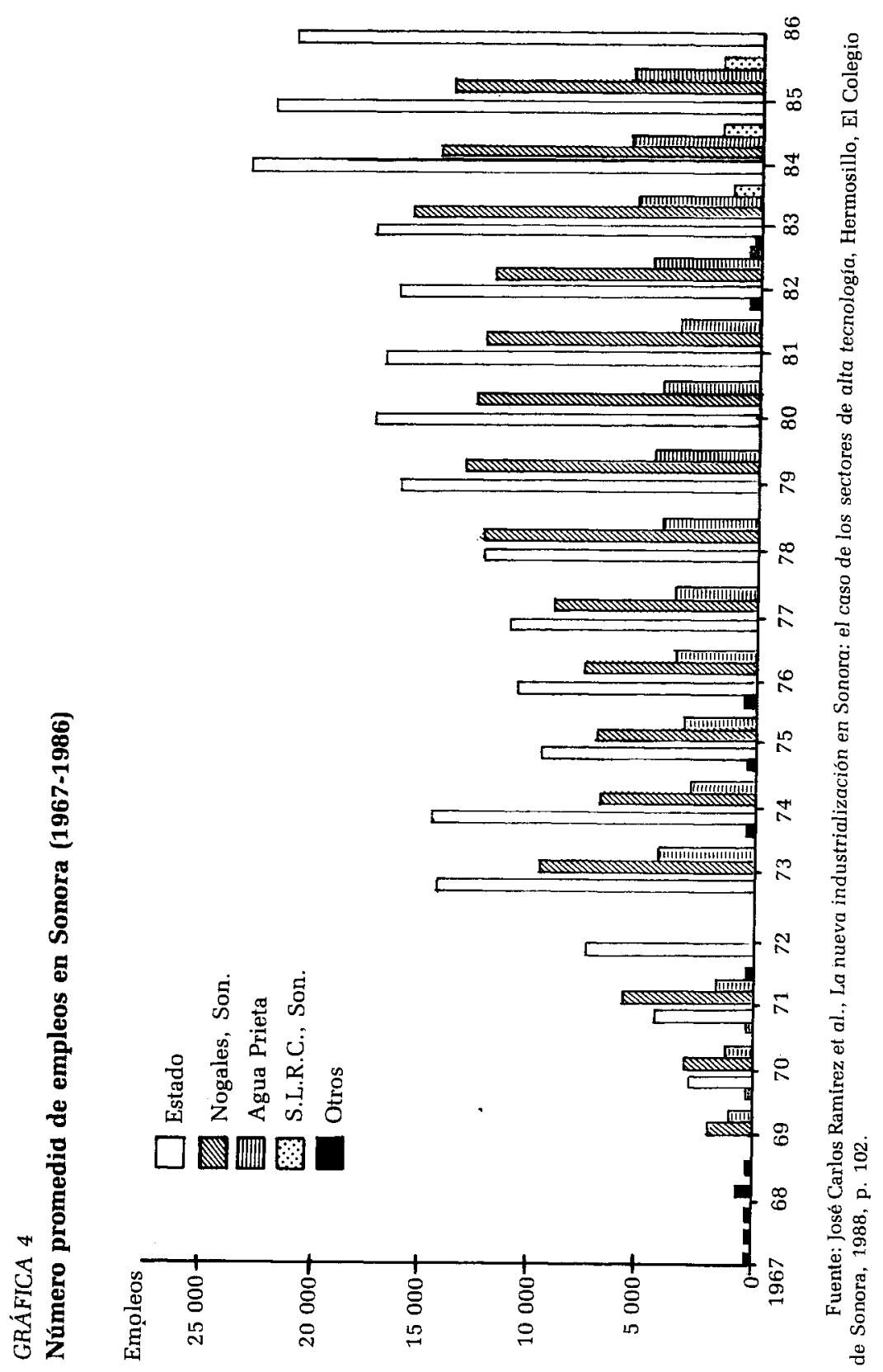


enfrentan los empleados. Además, como dato interesante, señalan que sólo un porcentaje de los operarios trabaja más de doce meses, variando las cifras de acuerdo al tamaño de la empresa: en las pequeñas (menores de 100) el porcentaje alcanza la tercera parte y en las grandes, como la PermaMex, a $50 \%$ de los trabajadores.

Sin embargo, la verdad es que el problema de la rotación es a menudo más complejo que las causas aducidas por los gerentes, debido a que éste se encuentra arraigado a las condiciones originarias del empleado, y en gran medida, a su inserción en el proceso de trabajo. Para ver con más detenimiento estos aspectos puntualizaremos los resultados obtenidos comparándolos con los logrados en otras encuestas.

1. Los trabajadores que se integran a la maquila son en su mayoría migrantes (en $73 \%$ ) del sexo femenino (pero en menor proporción que los hombres: 77 contra 71), solteras(os), de 25 años en promedio y con una nula experiencia migratoria o laboral previa. Llegan procedentes del interior del estado ( $40 \%$ ) y de cuatro entidades nacionales (33\%) movidos por el atractivo de la maquila y otras causas anexas ( $72 \%$ de ellas), pero sin contar más que con un nivel de educación secundaria y con escasa habilidad técnica. ${ }^{25}$

De esto último dan prueba dos encuestas que realizaron en el área Vania Muller y la Sedue hace 12 y 3 años, respectivamente, aunque con algunas diferencias. ${ }^{26}$ Por ejemplo, mientras que la Sedue estimó un porcentaje y una distribución de migrantes exactamente igual a nuestros cálculos (que hablan de una constante afluencia de migrantes), Muller encontró que $50 \%$ de los entrevistados tenía cinco o más años en Nogales, lo cual le sugería que la migración se encontraban en descenso. Por lo demás, esta autora coincide con nosotros en que estas características hacen de Nogales una plaza un tanto distinta a la de Tijuana, por ejemplo, no sólo porlla mayor participación de hombres en las maquilas, sino también por los más altos niveles de educación en promedio.

2. Fuera de las diferencias formales entre Nogales y Tijuana u otra frontera, lo cierto es que al momento de internarse a la producción los obreros siguen el mismo camino en todas partes: los contratan a prueba sin examen previo por espacio de 28-30 días, les asignan un supervisor que puede ser la compañera más antigua o los asesores de las plantas, y

25 Véase José Carlos Ramírez, op. cit., p. 105. Estos datos están basados en una muestra que El Colegio de Sonora realizó en octubre de 1985 en Nogales, Sonora. La encuesta fue aplicada a 259 trabajadores de las 17 industrias más representativas de todas las ramas (grandes, pequeñas y medianas) y constaba de una batería de 103 reactivos y dos matrices para detectar: calificación, historia migratoria y laboral, condiciones de vida y organización sindical, entre otras cosas. El muestreo fue proporcional estratificado y la selección se llevó a cabo aleatoriamente con una fijación definida por el peso del estrato.

26 Vania Muller op. cit., pp. 32-35 y Sedue, "Encuesta sobre vivienda y hacinamiento en Nogales", 1983, mimeo. 
les dan un entrenamiento que oscila entre un día y dos semanas. El entrenamiento rara vez sirve como ascenso para los obreros empleados en las empresas pequeñas y, con excepción de los varones más calificados y de mayor antigüedad, tampoco para los que laboran en las grandes. Pasado el periodo de prueba se les asigna una cuota de producción (no necesariamente) y se les expone a un ritmo tenso y monótono durante 9.5 horas por seis días. Esto provoca una deserción temprana en aquellos empleados que no cubren la cuota.

La combinación de estos ritmos intensivos con algunas deficiencias ambientales en el trabajo, han sido señaladas como otras causas importantes de abandono en la maquila, y quizá definitivas para algunas industrias altamente tóxicas. Sin embargo, éste es un aspecto que requiere un tratamiento más profundo, por lo cual remitimos al lector al trabajo de Denman sobre Nogales. ${ }^{27}$

Aquí sólo haremos mención brevemente de una causa más ligada con nuestros intereses y que tiene que ver con la forma como las maquilas reaccionan ante los cambios en los pedidos de la empresa matriz. Y para ello contestaremos también brevemente que estos cambios se han convertido con el tiempo en factores importantes de rotación por dos motivos: uno, por los reajustes y cierres intempestivos que provocan en algunas empresas; y dos por el régimen de contratación laboral al que obligan.

Para ilustrar el primer punto, nada mejor que remitir al lector al capítulo 3 del trabajo de Ramírez ya citado donde podrá comprobar que las bajas en los niveles de producción exigidos por la matriz se transforman casi inmediatamente en despidos en la maquila, en muchos casos inconstitucionalmente. Esto no quiere decir que éste sea el patrón seguido por todas las empresas, pues para desmentirlo se encuentran las plantas más grandes y prestigiosas como la Perma-Mex, sino por aquellas "empresas estadunidenses para las que una determinada cantidad de erogaciones adicionales puede significar pérdidas o ganancias en un año contable". ${ }^{28}$ Tales fueron los casos, por ejemplo, de Lassey de México en 1974 o de Bowmar en 1973.

Sin embargo lo que aquí importa es que estas situaciones son posibles, aún ahora, debido al estado de indefensión en que se encuentran los trabajadores sujetos a regímenes de contratación desventajosos (y aquí entramos al segundo punto). Según nuestra encuesta ningún trabajador de Nogales declaró estar sindicalizado pese que algunas de las empresas entrevistadas pertenecían a las 14 plantas que tenían contrato colectivo y con el Sindicato Progresista de la Maquila en Nogales.

27 C. Denman, Repercusiones de la mE en la salud, tesis de maestría en ciencias sociales: estudios regionales, 1987.

${ }_{28}$ M. Martínez del Campo, "Ventajas e incrementos de la actividad maquiladora en México", en Comercio Exterior, vol. 33, núm. 2, febrero de 1983, p. 150. 
Este desconocimiento de los derechos permite que las empresas puedan echar mano de trabajadores "especiales", como los estudiantes de secundaria de Nogales, en momento de auge, o deshacerse de otros en periodos de crisis, sin erogar gastos onerosos o sin tener que soportar protestas. De esa manera las plantas contribuyen a acelerar la rotación de aquellos trabajadores contratados sin ningún convenio firmado o que fueron incluidos en las listas negras.

3. Otras causas relacionadas con la alta rotación de empleos en la maquila sonorense tienen que ver con la deficiente reproducción de la fuerza de trabajo, en particular con los problemas de vivienda y salud. Aquí, como en el apartado anterior dichos problemas son mas pronunciados en unas empresas que en otras, aunque en cualquier caso la falta de casas o de atención a las enfermedades se debe a la inexistencia de un mercado de trabajo estable.

La existencia de un flujo constante de migrantes que se emplea por poco tiempo frena las aspiraciones de trabajadores por conseguir mejores condiciones de vida, debido a que de esta manera las maquilas no sienten la necesidad de reproducir a quienes sólo laboran eventualmente. Por eso, a pesar de los grandes esfuerzos realizados en materia de vivienda para evitar la huida de los trabajadores migrantes, la Sedue encontró en 1984 un déficit de 11625 casas en aquellas colonias de Nogales habitadas usualmente por familiares migrantes. ${ }^{29}$

Esta muestra, que incluía 801 jefes de familia, evidenció, en conformidad con nuestra encuesta, una carencia casi total de servicios públicos en 17 colonias marginadas y un hacinamiento extremo en casas construidas con material de desecho recogido de los basureros. Por lo que en esas condiciones no es raro que Nogales mantenga la tasa general de mortalidad más alta del estado o que el despido por enfermedad en la maquila sea un hecho diario.

Sobre esto último es importante destacar que las jornadas extenuantes, la exposición a sustancias tóxicas, el estrés y en general la deficiente reproducción diaria de los trabajadores influyen poderosamente en dos hechos señalados por los gerentes: la disminución del rendimiento del empleado después de un año y medio de trabajo continuo, y la deserción temprana por motivos de salud (abortos, infecciones respiratorias, etc.). De esto da fe una investigación realizada por El Colegio de Sonora en el iMSS de Nogales. ${ }^{30}$

${ }^{29}$ Por su importancia, Nogales es la ciudad de Sonora que presenta el más alto porcentaje de viviendas en mal estado, ya que a pesar de que otros lugares, como Agua Prieta o el mismo Hermosillo, presentan un problema similar, la situación no es tan crítica como en dicha frontera. Para más detalles sobre el nivel de deterioro de la vivienda en este lugar y su comparación con otros sitios en el estado, véase José Carlos Ramírez et al., "Subsistema de ciudades...", op. cit., cap. IV.

${ }^{30}$ C. Denman, op. cit., cap. iii. 
De lo anterior se deduce que no es posible tener un conocimiento cabal de la nueva incursión estadunidense en la entidad si se desconocen los cambios nacionales e internacionales que han acompañado el desarrollo de las maquiladoras y de la Ford. Y en particular si no se hace referencia a las transformaciones sufridas por las ET del ramo automotriz y electrónico en los últimos años.

Esto conviene retenerlo porque ni siquiera los patrones de operación de dichas plantas han permanecido constantes: han cambiado como lo han hecho también las causas que rigen su emplazamiento en los territorios poco industrializados, y ésa es una verdad que, a la luz de varios estudios, ${ }^{31}$ se ha vuelto casi evidente. Asi que para no vernos rebasados por el fenómeno, mencionaremos los tres grupos de factores que, según nosotros, han afectado más la nueva presencia estadunidense en Sonora.

El primero de ellos tiene que ver con los cambios ocurridos en las modalidades de la competencia internacional y, concretamente, con las estrategias tecnológicas y organizacionales adoptadas por las ET y sus gobiernos. De ello nos podemos dar cuenta si analizamos cada industria por separado. Por ejemplo en el caso de la Ford esas modalidades han tendido a desconcentrar gran parte de sus procesos productivos fuera de los Estados Unidos, debido a su mayor capacidad de integración con otros capitales externos. ${ }^{32}$ A diferencia de la Chrysler y de la General Motors, sus políticas de expansión han pasado a depender cada vez más de los convenios establecidos con otras empresas en el extranjero (por ejemplo con la Fiat, Alfa Romeo, etc.) que de sus decisiones internas en los Estados Unidos $\mathrm{Y}$ eso ha hecho que la viabilidad de proyectos como el de la planta Ford en Hermosillo haya estado supeditada más a los términos inscritos en los acuerdos de cooperación que a cualquier otro factor de localización industrial (como en las décadas pasadas); en este caso a los acuerdos de tecnología, administración y dirección celebrados entre ella y las compañías japonesas.

Otro tanto ocurre con las maquilas eléctricas y electrónicas (las más importantes del estado), pues es sabido que las fusiones de empresas llevadas a cabo desde 1982 por los ministerios de Estados Unidos (Secreta-

31 Véase por ejemplo Dieter Ernst, "La automatización basada en el uso de computadoras y la internacionalización de la industria electrónica. Implicaciones estratégicas para los países en desarrollo", en Isaac Minnian (coord.), Industrias nuevas y estratégicas de desarrollo en América Latina, México, CIDE, 1986 y Junne Gerd, "Automatización en los países en desarrollo" en Ciencia y desarrollo, núm. 59, 1984.

32 Para analizar los efectos de las políticas gubernamentales ensayadas desde 1951 (con H. S. Truman) por los gobiernos estadunidenses para desconcentrar la rama automotriz, véase Sergio Sandoval Godoy, op. cit., cap. 2. 
ría de la Defensa), Japón (MITI) y Europa (comisiones de la CEE), han alterado su contratación en los países anfitriones. En Sonora, este fenómeno ya empezó a sentirse, pues entre las empresas estadunidenses que ahí maquilan se encuentran filiales de la General Electric (recién fusionada con la RCA), Motorola y otras que mantienen contratos con la Secretaría de la Defensa norteamericana y que están expuestas a los cambios tecnológicos propios de su condicion.

Uno de esos cambios es la adopción de tecnología reprogramable que en la práctica, según Gerd Junne, ${ }^{33}$ podría inhibir la exportación de segmentos productivos o simplemente reducir el número de trabajadores contratados en aquellas actividades donde antes predominaba la maqu inaria rígida (textiles, por ejemplo). Asimismo hay que considerar la añeja competencia japonesa-norteamericana en la rama de productos eléctricoselectrónicos que tanto ha afectado a la maquila de la localidad, ${ }^{34}$ y que en la actualidad se encuentra en su punto crítico. Últimamente el gobierno norteamericano ha bloqueado la importación de semiconductores japoneses a los Estados Unidos con el propósito de proteger a su industria local, además de que ha impulsado la tecnificación de todas las fases del proceso productivo en los grandes consorcios para hacer frente a los orientales en otros mercados.

En una palabra, nos encontramos ante la presencia de ciertas condiciones variables en el plano internacional que exponen a la maquila electrónica y a la industria automotriz (Ford) a problemas de permanencia e integración desconocidas en el pasado.

El segundo grupo de factores, que últimamente ha afectado la presencia estadunidense en Sonora, está relacionado con la nueva actitud de los gobiernos de Estados Unidos y de México hacia las plantas ensambladoras, y en especial, al decisivo papel que éstas han pasado a jugar en los problemas fronterizos de ambos países. Veámoslo por partes.

Por el lado del gobierno mexicano se ha observado un apoyo sin precedentes al establecimiento de la industria automotriz y de la maquila en todo el territorio, después del rotundo fracaso observado en su política de exportación no petrolera entre 1978 y $1982 .{ }^{35}$ Desde entonces esas in-

33 Gerd Junne, op. cit., p. 33.

34 Para comprobarlo basta recordar que en 1977 Motorola cerró una de sus dos plantas (la más grande) debido a que la industria japonesa la desplazó de la fabricación de cristales de cuarzo para relojes electrónicos, o más recientemente, en 1985, el caso de la General Instrument, cuya venta en la rama de semiconductores para videojuegos y computadoras caseras disminuyó por presión de sus competidores estadunidenses (Magnavox, RCA y Sylvania) y japoneses (véase José Carlos Ramírez, op. cit., p. 92).

35 Como se recordará, esta política dejó de manifiesto que tan sólo el turismo y la maquila mantuvieron una elasticidad de exportación mayor que la unidad. En 1986 el crecimiento de estas dos actividades hizo posible que por primera vez desde 1979 , las manufacturas superaran las ventas de crudo (9 600 contra 6300 millones de dólares). Ambas aportaron un poco 
dustrias dejaron de ser consideradas como una simple fuente de divisas para convertirse en el centro de la actual restructuración productiva del país. De ello dan fe las modificaciones legales hechas en agosto de 1983 a los regímenes jurídicos de la maquila; la nueva disposición de 1985 sobre la participación extranjera en la rama metal-mecánica y todas las facilidades que ha dado el gobierno para convertir el sector de punta nacional (electrónico y automotriz) en pura actividad maquiladora.

Por parte del gobierno estadunidense la situación en cambio no parece muy clara, porque aun cuando sigue manteniendo una política hostil hacia ciertos productos mexicanos exportados a través del Sistema Geñeral de Preferencias, su posición frente a los sindicatos norteamericanos es de defensa hacia la exportación de segmentos productivos. E incluso, según información proporcionada por el Departamento de Comercio de California, el gobierno de Reagan ha puesto en marcha una política de aliento a la maquila para: a) reducir el enorme déficit comercial estimado en 169800 millones de dólares, sobre todo en la rama electrónica (que entre 1985 y 1986 sumó, en promedio, 8000 millones de dólares; b) enfrentar mejor la competencia internacional en el mercado de componentes de computadoras (monitores, impulsores de disco y fichas electrónicas de memoria), y c) contener la inmigración ilegal. La política contempla un crecimiento de establecimientos de $10 \%$ anual en los años noventa. ${ }^{36}$

En contra de las tendencias económicas internacionales descritas, este tipo de posiciones crea un clima de aceptación muy diferente al que existía en las dos décadas pasadas, máxime si consideramos el papel determinante de los Estados Unidos en la negociación de la deuda externa mexicana (nos referimos a su poder de negociación en las políticas liberadoras "sugeridas" por el FMI) y a su interés por encontrar un dique de contención a los miles de indocumentados devueltos a partir de la puesta en marcha de la ley Simpson-Rodino. La duda es si estas buenas disposiciones pueden resultar contraproducentes ante la creciente tecnificación de las fases productivas que actualmente se maquilan o ante las recientes amenazas de derogación de las fracciones 806.30 y 807.00 del Sistema de Tarifas y Aranceles de Estados Unidos (TSUSA) por parte de algunos congresistas.

Finalmente es interesante destacar, como tercer grupo de factores, las decisiones tomadas por ambos tipos de plantas al momento de internarse al país. Este es un aspecto poco atendido por quienes consideran las grandes tendencias generales del desplazamiento y desdeñan, como consecuen-

más de 2700 millones de dólares. Sobre el fracaso de la política consistente en impulsar las manufacturas nacionales con base en el excedente petrolero, véase Jaime Ros, "La crisis económica: un análisis general”, en Pablo González Casanova (ed.), op. cit., pp. 135-152.

36 Excélsior, Sección Financiera, 17 de enero de 1987, p. 1. 
cia, los movimientos que las plantas realizan para instalarse en determinadas plazas. Su esclarecimiento es un paso decisivo para comprender por qué Nogales, por ejemplo, tiene más empresas que Agua Prieta o por qué la Ford prefirió Hermosillo que Chihuahua.

Los resultados a los que llegamos en la frontera de Nogales son, aunque parciales, importantes para este fin. De los 23 gerentes ahí entrevistados, la mayoría contestó como principal causa del desplazamiento de su empresa los bajos salarios, seguido por mayores exenciones fiscales, el apoyo de los comités industriales, y la estabilidad política y social de la región (en esta última destaca el bajo nivel de sindicalización existente). Las empresas grandes (más de $\mathbf{5 0 0}$ trabajadores) de la rama eléctricaelectrónica señalaron, a su vez, como motivoś esenciales para lograr su traslado a Nogales la primera y cuarta razón, mientras que las pequeñas la primera y la segunda.

Sin embargo, este grupo de motivos no dice nada por sí solo si no consideramos el objeto básico de su traslado: la rápida ganancia. A decir de Vania Muller, éste es el deus ex machina escondido detrás de cualquier instalación "ya que las maquiladoras operan con el propósito de (lograr) utilidades (en el menor) tiempo. La ventaja a corto plazo es la que se busca en todos los aspectos ya que la gerencia siente que vive con el tiempo prestado". ${ }^{37}$ Esto no suena descabellado si tomamos en cuenta que el ahorro por trabajador, descontada la devaluación, asciende a 16000 dólares anuales en Nogales, según Sonitronies-Collection. ${ }^{38}$

Con la Ford se dio una situación parecida a la de las maquiladoras electrónicas gigantes, pues para su instalación se realizaron dos estudios de factibilidad económica y geográfica. Éstos permitieron seleccionar a México de entre otros países (Taiwán, Canadá y Portugal) y a Hermosillo de entre cuatro ciudades (Chihuahua, Ciudad Juárez, Matamoros y Nuevo Laredo). La última decisión se debió a los siguientes elementos:

...las condiciones excepcionales de la fuerza de trabajo [hermosillense], la oferta de la tierra libre de costo, el gasoducto Naco-Cananea-Hermosillo, las inmejorables condiciones de infraestructura industrial que proporcionó el gobierno (...) y la cercanía con el puerto de Guaymas; este último le facilitaba enormemente [a la Ford] la movilidad para el transporte de la producción, materias primas y equipos desde las puertos japoneses y de los Estados Unidos. ${ }^{39}$

Así que si sumamos los efectos combinados de estos tres grupos de factores más los derivados de la cambiante estructura de mercado y de costos que enfrentan la Ford y las maquiladoras en el plano internacional,

37 Vania Muller, op. cit., p. 34.

38 Sonitronies Collectron Plan Sheter, Tucson, 1986, mimeo.

39 Sergio Sandoval Godoy, op. cit., p. 159. 
nos percataremos de dos facetas distintivas de la nueva avanzada estadunidense en Sonora. La primera, que es la más importante, su gran autonomía de las decisiones de política interna, y la segunda, los elevados costos económicos y sociales que involucra su integración. Ambas se traducen en un caro y frágil proyecto de industrialización regional que cada vez resulta mas difícil de suplir.

Entonces, si la Ford y las maquiladoras han creado un segundo frente de reproducción social en la entidad, no es sólo por las características propias de su génesis y evolución (tan dependiente del exterior), sino también porque han desarrollado una red de funcionamiento y de conflictos totalmente ajena al medio local. Su proyecto industrial es por definición un proyecto de "extrañamiento social" y esa es una afirmación que ya ni el más cándido de los empleados de la Secofi puede poner en duda, sobre todo ahora que está de moda reconocer que la frontera es para el gobierno federal lo que hace tiempo fue Monterrey, Guadalajara y México para su política sustitutiva de importaciones. 